On Press 



\section{On Press}

\section{The Liberal Values That Shaped the News}

สี้า

MATTHEW PRESSMAN

Harvard University Press

Cambridge, Massachusetts

London, England

2018 
Copyright $(@ 2018$ by the President and Fellows of Harvard College

All rights reserved

Printed in the United States of America

First Printing

\section{Library of Congress Cataloging-in-Publication Data}

Names: Pressman, Matthew, 1981- author.

Title: On press : the liberal values that shaped the news / Matthew Pressman.

Description: Cambridge, Massachusetts : Harvard University Press, 2018. |

Includes bibliographical references and index.

Identifiers: LCCN 2018002541 | ISBN 9780674976658 (hardcover : alk. paper)

Subjects: LCSH: New York Times Company. | Los Angeles Times (Firm) |

Journalistic ethics-United States-History-2oth century. | Journalistic EthicsUnited States-History-21st century. | Liberalism-United States-History-2oth century. |

Liberalism-United States-History-21st century. | American newspapers-Objectivity.

Classification: LCC PN4888.E8 P74 2018 | DDC 174/.907-dc23

LC record available at https://lccn.loc.gov/2018002541

Cover photograph: photosipsak @ Getty Images

Cover design: Annamarie McMahon Why 
- For Lauren, with love and gratitude 
